\title{
Differences in Perceived Causes of Poverty between First and Third Year Economics Students in a Higher Education Institution
}

\author{
Nokwanda Maseko \\ School of Economic Sciences, North-West University, Vanderbijlpark, South Africa. \\ Email: nakita366@gmail.com \\ Diana Viljoen \\ School of Economics Sciences, North-West University, Vanderbijlpark, South Africa. \\ Email:Diana.Viljoen@nwu.ac.za \\ Paul-Francois Muzindutsi \\ School of Economics Sciences,North-West University, Vanderbijpark, South Africa. \\ Email:24754293@nwu.ac.za
}

\section{Doi:10.5901/mjss.2014.v5n21p245}

\section{Abstract}

Poverty is more than just a socio-economic issue, it is a human rights' issue as well. It is also an issue which most, if not all governments the world over have been unable to completely eradicate. Since its inauguration following the 1994 elections, the South African government has made the eradication of poverty one of its top priorities. Extensive research focusing on the causes of poverty has been done; and over the past few years, researchers have also recognised the need to focus on people's perceived causes of poverty as a way of figuring out strategies for alleviating poverty, and in the long-run eradicating it. The focus of this study was on determining if there are differences in the ways in which first and third year economics students perceive the causes of poverty. To achieve this, the study made used of a self-administered survey questionnaire. Descriptive statistics, one-way independent t-tests and analysis of variance (ANOVA) were applied to determine if there are in fact differences in the way these two groups of students perceive the causes of poverty, and also the extent of those differences. The results revealed that both first and third year students are more likely to blame poverty on structural factors; however, third year students were more likely than first year students to attribute poverty to structural factors. These results also revealed that the level of study in economics influence perceptions of the causes of poverty.

Keywords: Causes of poverty, fatalistic, structural, individualistic, economics students

\section{Introduction}

Globally, poverty remains one of the biggest challenges faced by governments and populations, with the majority of the affected people living in developing countries. It is therefore important to understand the factors that contribute to or cause poverty. Du Toit (2005) stated that it is important to learn more about poverty, as well as the factors maintaining it. Poverty assessments are often grouped into three major categories: the poverty profile, the causes of poverty as well as strategies to reduce poverty (Ngwane et al., 2003). The causes of poverty are perceived differently by various groups; for instance, children aged between 13 and 17 interviewed in Ethiopia attributed poverty to factors such as a weaker work ethic, extravagance and poor financial management (Tafere, 2012). Some people blame individualistic factors such as laziness; others see causes of poverty as structural; while other others perceive the causes of poverty to be fatalistic. In South Africa, the burden of poverty remains one that is unevenly spread amongst the different races, with the majority of those living in poverty being Black people. As the years pass, those affected by poverty seem to get younger and younger. This has made it important to focus discussions about poverty around young South Africans.

A survey by Letseka and Maile (2008) focusing on university drop-outs found that nearly $70 \%$ of families of university drop-outs can be classified as poor, or having low economic status. Coupled with racial inequality, the study found that some of the families of Black university drop-outs survived on wages as low as R1600 per month. Studies such as the one by Letseka and Maile highlighted the need for more research on poverty and its perceived causes among university students. Hence, this study assesses the perceptions of poverty between first year and final year students. This 
will identify whether students who are in the final year of study perceive poverty differently from those who are in their first year of study.

\section{Literature Review}

Understanding people's perceptions of the causes of poverty is important for the sake of a country's economic development (Lepianka et al., 2009). This is more so in a country like South Africa where over 60\% of the country's children live in conditions of poverty (Nicholson, 2012), and where the first generation since the end of apartheid has become eligible to vote in the national election. Often, assessments of poverty are grouped into three categories: determining who the poor are, why those people are poor, and the strategies to be used in the fight against poverty (Ngwane et al., 2003). The focus of this study is to determine what higher education institution students view to be the cause of poverty.

According to the literature (Davids, 2010; Ljubotina \& Ljubotina, 2007; Wollie, 2009), concentrating on the perceived causes of poverty does so under the view that the causes of poverty can be explained based on three different perspectives as established by Feagin (1972). These perspectives are as follows: poverty is the consequence of fatalistic factors (suggesting that factors out of people's control might be responsible for the poverty that people experience, for instance, those people might have bad luck); the second factor explains the causes of poverty in terms of structural factors (suggesting that political and socio-economic factors are at fault, for instance, society lacking social justice or people being exploited by the rich), the third factor states that people living in poverty do so as a result of their own doing (for instance, due to an inability to manage money, or wasting money on inappropriate items) (Shek, 2002).

In the initial Feagin (1972) study, the results showed that people tended to blame poverty on individualistic factors, and although these perceptions have changed over the years, there is still a high number of people who tend to blame themselves for living in poverty. This is exacerbated by the fact that society tends to attribute poverty to one's own shortcomings without taking into account external factors. Recent studies have revealed that age and educational level contribute to people's perception of poverty as an individualistic issue (Nasser et al., 2005; Tafare, 2012). This means that the lower one's educational level is, the more likely that person is to blame themselves for living in poverty. Those whose educational attainment is a bit higher are likely to attribute poverty to structural factors, as compared with fatalistic and individualistic factors. The reason for this might be that educated people might be better equipped to understand the intricate poverty theories and how they link up with actual economic scenarios to contribute to high poverty levels. For instance, high unemployment coupled with high illiteracy and declining economic growth will contribute to high poverty levels. Hence, an individual who understands these concepts may see causes of poverty as structural.

Age, coupled with education level appear to play a big role in influencing people's perceived causes of poverty. For instance, a study of poverty perceptions by Tafare (2012) found that young people aged between 13 to 17 year old blamed poverty on individualistic factors such as a poor work ethic and financial mismanagement. This is contrary to the study by Sun (2001), which found that Social work students tended to blame the causes of poverty on structural factors. The study by Sun (2001) also indicated that Non-Social work students blamed poverty on individualistic factors. This suggests that those who have been exposed to social sciences where concepts such as poverty are studied would be in a position to understand external factors that contribute to high levels of poverty, instead of merely looking at one's own shortcomings. People's opinions regarding the causes of poverty may therefore differ based on the studies one has been exposed to. Considering that third year economics students have been exposed to the courses of Development Economics, they are expected to have a have a better understanding of concepts such as poverty than first years. Hence, their perceptions of the causes of poverty may be different from that of first years. This study focuses on determining whether there is a difference or not in the way that first year and third year economics students perceive the causes of poverty.

\section{Methodology}

\subsection{Research instrument}

This study followed quantitative research design with the use of survey questionnaire. In order to establish the perceived causes of poverty of the participants, the Feagin scale was used. Shek (2004) explains that this scale comprises twelve statements to which the participants are asked to indicate the level of agreement or disagreement using a likert scale of 1 to 5. The scale has five different options: Strongly agree (5), agree (4), not sure (3), disagree (2) and strongly disagree (1). 
The scale is composed of 12 statements that can be grouped into three factors namely: fatalistic, structural and individualistic factors. Fatalistic factors include four statements: they lack luck, they have bad fate, they have encountered misfortunes, and they are born inferior. The structural factor has five statements: they are not motivated because of welfare, the distribution of wealth in society is uneven, the society lacks social justice, they are exploited by the rich, and they lack opportunities due to the fact that they live in poor families. The individualistic factor includes three statements: they waste their money on inappropriate items, they lack the ability to manage money, and they do not actively seek to improve their lives.

\subsection{Sampling and description of participants}

Purposive sampling method was used to collect data for first and third year Economics students from North-West University's Vaal Triangle Campus. The data was collected during class time so as to have access to as many participants as possible to leave room for any questionnaire errors that might have occurred. All participants were informed of the purposes of the study, and were also informed that participation was voluntary. Out of 118 participants who participated in this study, 54 were first year participants, while 64 were third years. All participants were registered for a degree in Economics.

Demographic information of participants for both first and third year students is shown in Table 1. Amongst the first year students, $63.0 \%$ of the participants were female and $37.0 \%$ were male; while amongst third year students $67.2 \%$ were female, and only $32.8 \%$ were male. Participants were aged between 18 and 23 . A high percentage of the first year students (66.7\%) were aged 19, while the highest percentage of third year students (45.3\%) were aged 21. However, while the age of the participants was important for this study, the most important demographic was the year of study, since the intention of this study was to determine the differences in the perceptions of the causes of poverty between participants in different years of study.

Table 1: Demographic information (First years, $N=54$; Third years, $N=64$ )

\begin{tabular}{|c|c|c|c|c|c|}
\hline & & \multicolumn{2}{|c|}{ First years } & \multicolumn{2}{|c|}{ Third years } \\
\hline \multicolumn{2}{|c|}{ Variable } & $\mathrm{N}$ & Percent & $\mathrm{N}$ & Percent \\
\hline \multirow[t]{2}{*}{ Gender } & Males & 20 & 37,0 & 21 & 32,8 \\
\hline & Females & 34 & 63,0 & 43 & 67,2 \\
\hline \multirow[t]{2}{*}{ Race } & Black & 41 & 75,9 & 55 & 85,9 \\
\hline & Non-Black & 13 & 24,1 & 9 & 14,1 \\
\hline \multirow[t]{6}{*}{ Age } & 18 years & 10 & 18,5 & 0 & 0.0 \\
\hline & 19 years & 36 & 66,7 & 0 & 0.0 \\
\hline & 20 years & 8 & 14,8 & 12 & 18,8 \\
\hline & 21 years & 0 & 0.0 & 29 & 45,3 \\
\hline & 22 years & 0 & 0.0 & 13 & 20,3 \\
\hline & 23 years & 0 & 0.0 & 10 & 15,6 \\
\hline \multirow[t]{2}{*}{ Home area } & Township & 24 & 44,4 & 31 & 48,4 \\
\hline & Non-Township & 30 & 55,6 & 33 & 51,6 \\
\hline
\end{tabular}

\section{Results and Discussion}

\subsection{Factor loadings: first year and third year students}

Table 2 and 3 show the factor loadings for the participants based on the year of study. For students in the first year of study, reliability statistics reveal a KMO of .639 and a Bartlett's Test of sphericity significant at $p=.000$, which is much lower than the .05 that is regarded as the highest this level can be (Pallant, 2010). These results are better than those of third year students where the KMO was .552, which is just above the acceptable level of .50. On the other hand, the Bartlett's test of sphericity revealed levels significant at $p=.000$, which is much lower than the .05 minimum requirement. As found in other studies (Davids, 2010; Shek, 2004; Hunt, 2004), the factor loadings for the first and third year students extracted three factors. For first year students, factor 1 has an initial eigenvalue of 3.481 , which explains $29.007 \%$ of total variance, while factor 2 has an initial eigenvalue of 2.091, which explains $17.425 \%$ of total variance, and factor 3 has an initial eigenvalue of 1.547 , which explains $12.891 \%$ of total variance. Cumulatively, these factors explain $59.322 \%$ of total variance. As with the data for the first year students, the factor loadings for third year students extracted three factors. 
Factor 1 has an initial eigenvalue of 2.423, which explains $20.194 \%$ of total variance, while factor 2 has an initial eigenvalue of 2.188 , which explains $18.233 \%$ of total variance, and factor 3 has an initial eigenvalue of 1.807 which explains $15.058 \%$ of total variance. Cumulatively, these factors explain $53.485 \%$ of total variance.

Table 2: Factor loadings, first year students

\begin{tabular}{|c|c|c|c|}
\hline & \multicolumn{3}{|c|}{ Component } \\
\hline & 1 & 2 & 3 \\
\hline They lack luck & .840 & & \\
\hline They have bad fate & .854 & & \\
\hline They have encountered misfortunes & .594 & & \\
\hline They are born inferior & 685 & & \\
\hline They are not motivated because of welfare & & & .459 \\
\hline Distribution of wealth in society is uneven & & & .798 \\
\hline The society lacks social justice & & & .728 \\
\hline They are exploited by the rich & & & .605 \\
\hline They lack opportunities due to the fact that they live in poor families & & & .431 \\
\hline They waste money on inappropriate items & & .894 & \\
\hline They lack the ability to manage money & & .857 & \\
\hline They do not actively seek to improve their lives & & .816 & \\
\hline
\end{tabular}

Table 3: Factor loadings, third year students

\begin{tabular}{l|c|c|c|}
\hline & \multicolumn{2}{|c|}{ Component } \\
\cline { 2 - 4 } & $\mathbf{1}$ & $\mathbf{2}$ & $\mathbf{3}$ \\
\hline They lack luck & & & .851 \\
They have bad fate & & & .826 \\
They have encountered misfortunes & & .548 \\
They are born inferior & & .378 & .266 \\
They are not motivated because of welfare & & .603 & \\
Distribution of wealth in society is uneven & & .676 & \\
The society lacks social justice & & .582 & \\
They are exploited by the rich & & .604 & \\
They lack opportunities due to the fact that they live in poor families & .807 & \\
They waste money on inappropriate items & .863 & \\
They lack the ability to manage money & .825 & & \\
They do not actively seek to improve their lives & & \\
\hline
\end{tabular}

\subsection{Comparison responses between first year and third year students}

Further analysis (Table 4) revealed that first year economic students perceive poverty to be the result of structural factors, with $51.9 \%$ of the participants agreeing; as compared to $60.9 \%$ of third year economics students. The data also shows that of the 54 first year participating first year students, $48.1 \%$ perceive poverty to be the outcome of fatalistic factors, while $46.30 \%$ of the participants blamed poverty on individualistic factors. On the other hand, $51.6 \%$ of third year students attributed poverty to fatalistic factors, while $53.1 \%$ attributed poverty to individualistic factors. Overall, the results show that first year economics students are as likely as third year economics students to attribute poverty to structural factors. However, where third year economics students were more likely to blame poverty on individualistic factors, first year economics students were more likely to blame poverty on fatalistic factors, with the percentages at $53.1 \%$ and $48.1 \%$ respectively. These results are in line with studies of students studying social sciences were more likely to attribute poverty to structural factors. For instance, Sun (2001), found that Social work students were more likely than non-social work students to perceive poverty as the result of structural factors. The study by Sun (2001) also found that taking out the study of Social work as a major subject altered the results, with more students likely to attribute poverty to individualistic factors. 
Table 4: Cross tabulation perceptions within two levels of study

\begin{tabular}{|c|c|c|c|c|c|}
\hline \multirow{2}{*}{\multicolumn{3}{|c|}{ Factors }} & \multicolumn{2}{|c|}{ Level of study } & \multirow[b]{2}{*}{ Total } \\
\hline & & & First year & Third year & \\
\hline \multirow[t]{6}{*}{ Fatalistic status } & Non-Fatalistic & Count & 28 & 31 & 59 \\
\hline & & Percentage & $51.9 \%$ & $48,4 \%$ & $50,0 \%$ \\
\hline & Fatalistic & Count & 26 & 33 & 59 \\
\hline & & Percentage & $48.1 \%$ & $51.6 \%$ & $50.0 \%$ \\
\hline & Total & Count & 54 & 64 & 118 \\
\hline & & Percentage & $100.0 \%$ & $100.0 \%$ & $100.0 \%$ \\
\hline \multirow[t]{6}{*}{ Structural status } & Non-Structural & Count & 26 & 25 & 51 \\
\hline & & Percentage & $48.1 \%$ & $39.1 \%$ & $43.2 \%$ \\
\hline & Structural & Count & 28 & 39 & 67 \\
\hline & & Percentage & $51.9 \%$ & $60.9 \%$ & $56.8 \%$ \\
\hline & Total & Count & 54 & 64 & 118 \\
\hline & & Percentage & $100.0 \%$ & $100.0 \%$ & $100.0 \%$ \\
\hline \multirow{6}{*}{ Individualistic status } & Non-individualistic & Count & 29 & 30 & 59 \\
\hline & & Percentage & $53.7 \%$ & $46.9 \%$ & $50.0 \%$ \\
\hline & Individualistic & Count & 25 & 34 & 59 \\
\hline & & Percentage & $46.3 \%$ & $53.1 \%$ & $50.0 \%$ \\
\hline & Total & Count & 54 & 64 & 118 \\
\hline & & Percentage & $100.0 \%$ & $100.0 \%$ & $100.0 \%$ \\
\hline
\end{tabular}

The results for the third year participants are far closer to the findings of Sun (2001). This could be attributed to the fact that third year economics students are more likely than first year students to be better informed of the intricacies that contribute to poverty status, which are beyond the control of those who are poor. These could be factors such as poor distribution of wealth within the society, or an inability to take advantages of economic opportunities due to being part of a poor family.

\subsection{Mean comparison}

A comparison of the mean was used to test whether perception of the causes of poverty differ between first year and third year students. Table 5 summarises the group statistics of the three perceptions of the causes of poverty among these two groups of students. A major difference between the mean was observed within the structural index, where third year students tend to perceive causes of poverty more structural than first year students. For fatalistic and individualistic perceptions the mean score are slightly higher within the group of first year students. This cross tabulation suggests that a large percentage of third year students considered the causes of poverty to be structural, compared to the percentage of first year students who attributed poverty to structural factors.

Table 5: Group Statistics for mean comparison

\begin{tabular}{cccccc}
\hline & Level of study & N & Mean & Std. Deviation & Std. Error Mean \\
\hline \multirow{2}{*}{ Fatalistic index } & First year & 54 & 2.4704 & 0.81787 & 0.11130 \\
& 3rd year & 64 & 2.4656 & 0.57022 & 0.07128 \\
Structural index & First year & 54 & 3.2037 & 0.79217 & 0.10780 \\
& 3rd year & 64 & 3.7109 & 0.74298 & 0.09287 \\
\multirow{2}{*}{ Individual index } & First year & 54 & 3.0676 & 1.08796 & 0.14805 \\
& 3rd year & 64 & 2.9739 & 1.06816 & 0.13352 \\
\hline
\end{tabular}

The independent t-test and the analysis of variance (ANOVA) were used to test for equality of the means. Results of the independent t-test, in Table 6, show that the null hypothesis for equality of the means cannot be rejected within the fatalistic and structural indices. This implies that means are not different within these two indices; suggesting that fatalistic and individualistic perceptions of the causes of poverty are similar among first year and third year students. Within structural index, the mean difference is statistically significant at the $1 \%$ level of significance, implying that the null hypothesis for equality of means is rejected. This suggests that first year and third year students perceived structural causes poverty differently. These results are confirmed by the ANOVA (Table 7), which also shows that the variability of means is not equal within structural index. Thus, first and third year economics students perceive structural causes of poverty differently; where third years tended to blame structural factors for causing poverty. These findings suggest that 
third year economics students use their economics knowledge to link the causes of poverty with structure factors such as the economic system.

Table 6: Independent T-test for equality of means

\begin{tabular}{ccccc}
\hline & $\mathbf{t}$ & Sig. (2-tailed) & Mean Difference & Std. Error Difference \\
\hline Fatalistic index & 0.037 & .971 & .00475 & .12831 \\
Structural index & -3.584 & .000 & -.50723 & .14151 \\
Individual index & .471 & .639 & .09369 & .19905 \\
\hline
\end{tabular}

Table 7: ANOVA between the two groups

\begin{tabular}{ccccc}
\hline & Sum of Squares & Mean Square & F & Sig. \\
\hline Fatalistic index & .001 & .001 & .001 & .971 \\
Structural index & 7.535 & 7.535 & 12.848 & .000 \\
Individual index & .257 & .257 & .222 & .639 \\
\hline
\end{tabular}

\section{Conclusions}

The focus of this study was on determining the differences in the perceived causes of poverty between first year and third year Economics students in a South African higher education institution. Results of the analysis revealed that the majority of students, regardless of year of study blamed poverty on structural factors. However, a higher percentage of third year students were more likely than first year students to blame poverty on structural factors. Where third year students were more likely to blame poverty on individualistic factors, first year students were more likely to blame fatalistic factors. Findings of this study revealed that the biggest difference amongst these two groups of students was on the structural factors, while the difference among the fatalistic and individualistic factors was negligible. These results also proved to be in line with past studies suggesting that the level of education and field of study influence perceptions of the causes of poverty, with those who are more likely to be better informed about poverty being far more likely to attribute poverty to structural factors.

\section{References}

Davids, Y.D. (2010). Explaining poverty: A comparison between perceptions and conditions of poverty in South Africa. Cape Town: Stellenbosch University (Dissertation - PhD).

Du Toit, A. (2005). Chronic and structural poverty in South Africa: challenges for action and research. Programme for Land and Agrarian Studies, University of the Western Cape, PLAAS Chronic Poverty and Development Policy Series No.6.

Feagin, J.R. (1972). Poverty: we still believe that God helps those who help themselves, Psychology Today, 6, 101-129.

Hunt, M. O. (2004). Race/Ethnicity and Beliefs about Wealth and Poverty. Social Science Quarterly, 85(3), 827-853.

Lepianka, D., Van Oorschot, W. \& Gelissen, J. (2009). Popular explanations of poverty: a critical discussion of empirical research. Journal of Social Policy, 38(3), $421-438$.

Letseka, M. \& Maile, S. (2008). High University drop-out rates: A threat to South Africa's future. HSRC policy brief. Pretoria: HSRC.

Ljubotina, O.D. \& Ljubotina, D. 2007. Attributions of poverty among Social Work and

Non-Social Work students in Croatia. Croatia Medical Journal, 2007(48), 741-749.

Nasser, R., Singhal, S. and Abouchedid, K. (2005). Causal Attributions for Poverty among Indian Youth. Current Research in Social Psychology, 11(1), 1-13.

Ngwane, A. K., Yadavalli, V, S, S. \& Steffens, F. E. (2003). Poverty in South Africa: statistical inference for decomposal poverty measures. Development Southern Africa, 20(2), 283-291.

Nicholson, Z. (2012). Most black SA kids live in poverty - study. IOL news, 18 Oct. [Online] Available http://www.iol.co.za/news/southafrica/most-black-sa-kids-live-in-poverty-study-1.1405705\#.UpMMMulaySk (April 3, 2013).

Pallant, J. (2010). SPSS survival manual: A step by step guide to data analysis using SPSS for Windows (Version10). Crows Nest, Australia: Allen \& Unwin.

Shek, D. T. L. (2002). Chinese adolescents' explanations of poverty: the perceived causes of poverty scale. Adolescence, 37 (148), $789-803$.

Shek, D. T. L. (2004). Beliefs about the causes of poverty in parents and adolescents experiencing economic disadvantage in Hong Kong. Journal of Genetic Psychology, 165 (3), 272-292.

Sun, A. P. (2001). Perceptions among social work and non-social work students concerning causes of poverty. Journal of Social Work Education, 37 (1), 161-174.

Tafere, Y. (2012). Children's experiences and perceptions of poverty in Ethiopia. Working paper 85. London: Young Lives, Oxford Department of International Development (University of Oxford).

Wollie, C.W. (2009). Causal attributions for poverty among youths in Bahir Dar, Amhara region, Ethiopia. Journal of Social, Evolutionary, and Cultural Psychology, 3(3), 251-272. 